\title{
J(G)
}

JOTS, 2/1, 2018: 67-83

\section{Bilge Kagan (Doğu 41) Yazıtındaki NIńTYn İbaresi Üzerine}

\section{On the Phrase NIńTYn in Bilgä Qayan Inscription (East 41)}

\author{
Erdem UÇAR \\ ( İzmir / T urkey) \\ E-mail: merdemu@gmail.com
}

On the 41st line of the eastern side of the Bilgä Qayan inscription there is a phrase in the form of NIńTYn. However, this phrase is damaged today in the original inscription. In the old copies of the inscription, this phrase is found as N"̈ńTYn, NIATYn, NInčTYn and NIńTYn. For this reason, the phrase has been read differently. In this article, the previous reading proposals will be evaluated and the meaning of reading will be emphasized.

Key Words: transcription, Bilgä Qayan inscription, ańıtayın. 
Bilge Kagan yazıtının doğu cephesinin 41. satırındaki NIńTYn, yazıtta bugün hasar görmüş durumdadır. Yazıtın erken dönemde alınan kopyalarında da ibare farklı şekillerde gösterilmiştir. Bu durum da ibarenin farklı olarak okunup anlamlandırılmasına neden olmuştur.

Aşağıdaki tabloda, şimdiye kadar filologların bu ibare hakkındaki okuma ve anlamlandırma teklifleri kronolojik olarak sıralanmıştır:

\begin{tabular}{|c|c|c|}
\hline Neşir & Yazıçevrim & Anlamlandırma \\
\hline Radloff 1895: 66-67 & anı atayın & 'onu atayım' \\
\hline Thomsen [1896] 2002: 190-191 & $\begin{array}{l}\text { anı ayltayın } \\
{[\sim \text { anitayin } \sim \text { aytayın }(?)]}\end{array}$ & 'onu isteyeyim (?)' \\
\hline Radloff 1897: 145b, 166a & anı ınçıtayın & 'onu cezalandırayım' \\
\hline Vambéry 1899: 81 & anı injiteyin & 'incitmek' \\
\hline Orkun 1936: 68 & anı ayıtayın & 'onu talep edeyim' \\
\hline Malov 1959: 14, 18, 21 & anı ańıtayın & 'onu cezalandırayım' \\
\hline Tekin 1968: 245, 278 & anı ańıtayın & 'onu korkutmak için' \\
\hline Ergin 1970: 28, 69 & anı ańitayın & 'onu korkutayım' \\
\hline Aydarov 1971: 313 & ani anitayın & 'onu cezalandırayım' \\
\hline Clauson 1972: $268 \mathrm{~b}$ & anı ayıtayın & $\begin{array}{l}\text { 'ondan açıklama talep } \\
\text { etmek' }\end{array}$ \\
\hline $\begin{array}{l}\text { Abdurahmonov-Rustamov } \\
\text { 1982: } 130\end{array}$ & anı ańıtayın & 'onu korkutayım' \\
\hline Tekin 1988: 50-51 & anı ańitayin & 'onları korkutayım' \\
\hline Erdal 1991: 764 & ayltayin & $\begin{array}{l}\text { 'ondan açıklama talep } \\
\text { etmek' }\end{array}$ \\
\hline Şükürlü 1993: 261, 266 & anı anitayın & 'ona anlatayım' \\
\hline Karcaubay 2003: 197, 205 & anı ayıtayın & 'onu cezalandırayım' \\
\hline Bazilhan 2005: 96 & anı ança tuyun & 'onu şöyle tutayım (?)' \\
\hline Tuguşeva 2008: 54, 63 & anı ańitayın & 'onları korkutayım' \\
\hline Recebli 2009: 337, 347 & anı ayıtayın & 'onu cezalandırayım' \\
\hline Berta 2010: 156, 195 & anı ańıtayın & 'onu sorgulayayım' \\
\hline Ölmez 2012: 130, 145 & anı ańıtayin & 'şunları bir korkutayım' \\
\hline Şaymerdinova 2014: 233, 242 & anı ayıtayın & 'onu cezalandırayım’ \\
\hline Hudiyev 2015: 249, 255 & anı anitayın & ‘ona anlatayım’ \\
\hline
\end{tabular}




\section{J(৫)}

\begin{tabular}{||l||l|l||}
\hline Şirin 2016: 472 & anı ańıtayın & $\begin{array}{l}\text { 'korku salmak, korkut- } \\
\text { mak, tedhiş etmek, yıl- } \\
\text { dırmak' }\end{array}$ \\
\hline \hline Ercilasun 2016: 580-581 & anı ańıtayın & 'onları korkutayım' \\
\hline \hline Aydın 2017: 95 & anı ańıtayın & 'onları korkutayım' \\
\hline \hline
\end{tabular}

MALOV, ańt- 'cezalandırmak' okuyuşunu desteklemek için bu fiil ile alakalı Yakutça aya 'vah!', ayı ‘suç, günah' ile Uygurca ayıg ve ańıg ‘kötü ve fena' kelimelerini tanık olarak göstermiştir (1959: 90b).

CLAUSON, yazıtta ańıtayın değil, ayıtayın 'to demand (an explanation)' olduğunu belirtmiştir (1972: 268b).

ERDAL, CLAUSON ile aynı fikirdedir, çünkü Fin Atlası'nda D (ń) işareti belirsizdir. Dolayısıyla ańtt- diye bir fiil mevcut değildir (1991: 764, dip. 498).

TUGUŞEVA, anıt- 'korkutmak' fiilinin *ań-'in (> aymak) ettirgen çatısı olduğunu, bu kökten teşkil edilen aymanç'in 'korku, dehşet' bulunduğunu ifade etmiştir (2008: 63, dip. 115).

TEKIN, Fin Atlası'ndaki ńTYn şeklindeki kayda güvenilmesi gerektiği kanaatindedir. Ayrıca, RADLOFF'un inçıtayın 'cezalandırayım' okunuşunun böyle bir kelime Eski Türkçede olmadığı için kabul edilemeyeceğini belirtir. Eğer burada /1/ ile başlayan bir kelime olsaydı bunun yazılması gerektiğini söylemiştir. Yazitlarda, 3 işareti $₹$ veya 3 işaretine çok benzediği için RADLOFF kelimeyi /nç/'li olarak düşünmüş olmalıdır. TEKIN'e göre, Uygurcada geçen ayınç 'korku', aymanç 'korku', ayın- 'korkmak' ve ayman- 'korkmak' kelimeleri aslında tanıklanmamış farazî *ay- köküne dayanmaktadır (krş. Mo. ayu- 'korkmak'). Bu nedenle, yazıtlardaki kelime /ń/'li olmalıdır (1988: 109).

TEKIN, Altaic Etymologies I başlıklı makalesinde de Eski Türkçe ayın- 'korkmak' (<*ay-ın-) ile Moğolca ayu- 'korkmak' denkliğini teklif etmiştir (1996: 267). DOERFER, TEKIN'in iddia ettiği ańıt- ile ayınç ilişkisinin pek mümkün olmayacağını düşünür, çünkü Eski Türkçedeki /ń/, Moğolcada /n/'dir, mesela koń = konin 'koyun'. Bu anlamda, Moğolcada beklenen fiil, *anu-şeklinde değil, ayu-şeklinde olmalıdır (1992: 17). 


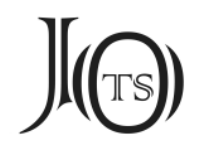

İbarenin şimdiye kadar çeşitli şekillerde okunmasının nedeni yazıtın orijinalindeki harflerin farklı yorumlanmasından kaynaklanmaktadır. Bugün ibarenin geçtiği kısım epey tahrip olmuştur. Bu durum, muhtemelen 125 sene önce de aynıdı, çünkü Fin Atlası'nda N'D \$ $3 \mathbf{N}$ ) NüńTYn ibaresindeki $\mathbf{N}, 3$ ve $\$$ işaretleri daha 1892'de emin olunamadığı için silik olarak gösterilmiştir (Inscriptions de l'Orkhon 1892: 12). RADLOFF (1895: 66; 1896: C) ve ALYILMAZ (2005: 132), N işaretini $\boldsymbol{\Gamma}$ ile değiştirmiştir. THOMSEN de aynı görüştedir. Dolayısıyla bu harfin \ olduğu kesindir. Yazıtların kopyalarında görüş birliğine varılamayan harf ise 3. sıradaki 3 işareti olmuştur. Buna göre, 3. sıradaki işaret RADLOFF'ta ilk önce $\checkmark$, sonra ise 3 şeklinde, Fin Atlası ve Alyılmaz 2005'te de 3 şeklindedir. O hâlde, ibare

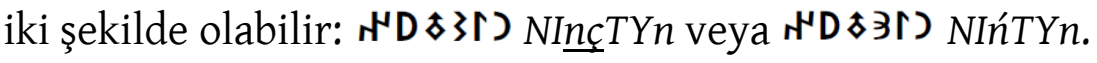

Yazıt, uzun süre açık alanda kaldığı ve parçalandığı için yazılı yüzeyler önemli ölçüde tahrip olmuştur (Alyılmaz 2005: 121). Bu durum da cümlenin bağlamının tam olarak anlaşılmasını engellemektedir. İbarenin geçtiği bağlamı anlamak için 40. ve 41. satırlara bakalım. Bununla beraber, satırlardaki 'takribî’ eksik harf sayısını da göstermeye çalışalım:

40. satir

$<\ldots>[\sim 10$ harf $]<\ldots>$ GqyA : y(é)r(i)n(e)rü : subın(a)ru : kontı : bir(i)ye k(a)rluk : bod(u)n t(a)pa : süle t(é)p : tud(u)n : y(a)mt(a)r(1)g 1tt(1)m b(a)rd1 <...> [ 30 harf] élt(e)b(e)r : yok bolm(1)ş : in(i)si : bir qwrG<...> [ 45 harf $]$

41. satir

<...> [ 9 harf] (a)rk(1)ş1 : k(e)lm(e)di : (a)nı nç̧TYn / ńTYn : tép sül(e)d(i)m : kor(1)gu : (i)ki üç : kiş(i)l(i)gü : t(e)z(i)p b(a)rd1 : k(a)ra bod(u)n : k(a)g(a)n(1)m : k(e)lti tép : ̈̈g<...>qA [ 30 harf] : at bért(i)m kiç(i)g (a)tl(1)g(1)g <... [ 45 harf]

İbarenin geçtiği bölümde 'gelmeyen/ulaşmayan' bir arkış'tan bahsediliyor. Bu arkış kime aittir? İbaremizdeki anı 'onu' zamiri kimin veya neyin karşıllı̆̆ında kullanılmıştır? 41. satırdaki kara bodun kaganım kelti cümlesindeki kara bodun ve kagan hangi halkı işaret etmektedir? Çoğu neşirde 40. satıra bakılarak 41. satırda da Karluklardan bahsedildiği düşünülmüştür. Ancak doğu cephesi metninde pek çok olayın hızlı geçişlerle sıralandığı görülmektedir. 40. ve 41. satırın ortasında 


\section{$J(\Theta)$}

ve sonunda yıpranmış kısımlardaki cümleler hakkında hiçbir bilgiye sahip değiliz. Belki de burada başka bir halktan bahsediliyordur. Bu konuda kesin bir şey söylenmesi oldukça zordur.

İbare, şu cümlenin içerisinde geçmektedir: $(a) r k(1) s ̧ ı k(e) l m(e)$ di NInçTYn / NIńTYn tép sül(e)d(i)m. Cümlede, süledim 'askerî sefer düzenledim' diyen Bilge Kagan'dır. Bilge Kagan'ın askerî sefer düzenlemesinin iki nedeninin olduğu düşünülebilir: 1. arkışı kelmedi ve 2. NInçTYn / NIńTYn tép.

Bunlardan ilki olan arkış gelmemesi, yani kervanın ulaşmaması askerî sefer için önemli bir nedendir. CLAUSON, buradaki arkış'ı 'elçi' ile tercüme etmiştir (1972: 217a), ancak Eski Türkçede, arkış’ın bunun dışında bir de 'kervan' anlamı vardır. Yazıtlarda bu anlamda geçtiği yerler bulunmaktadır. Ancak arkış'ın 'kervan' temel anlamının altında aslında 'vergi' anlamı yatmaktadır. CHAVANNES'e göre, Türk Kağanlığı'nda bir halkın kağana bağlılı̆̆ını gösteren iki alâmet vardı: vergi ve ok (1903: 27; Erkoç 2008: 75, dip. 156). Bunlardan ilkini yazıtlardan da öğrenmek mümkündür. Mesela, Bilge Kagan, Basmılların Iduk Kut ünvanlı idarecisi vergi vermediği, yani 'arkış göndermediğgi' için 703'te onlara askerî sefer düzenlemiştir: yégirmi yaşıma basmıl ıduk <k>ut uguşum bodunu<m> erti arkış ıdmaz téyin süledim (BK D25). Dolayısıyla, arkış'ın gelmemesini askerî seferin düzenlenmesi için bir sebep olarak düşünmek pekâlâ mümkündür.

Şimdi, askerî seferin ikinci nedeni olan NInçTYn / NIńTYn ibaresi üzerinde duralım. Fin Atlası ve Alyılmaz 2005'teki kopyalarda ibarenin sorunlu kısmının ńTYn şeklinde gösterilmesi, ibarenin doğru okunuşunda oldukça önemlidir. Bu durumda atayın, ınçıtayın, aytayın, ayıtayın, ayıtayın ve ança tuyun şeklindeki okumaların doğru olma ihtimali azalmaktadır.

$\exists$ işareti hakkında şimdiye kadar birçok görüş ifade edilmiştir. Bu konuda yapilan son araştırmada 3 işaretinin ön damak ünsüzü olduğu ve tek bir sesbirime karşlık geldiği ve anlam ayırıcı özellikte olduğu gösterilmiştir (Sultanzade 2017: 207-209). Bu nedenle, ND\$3 J ibaresinin Tekin 1968'deki gibi (a)n (a)ń(i)t(a)y(i)n şeklinde okunması gerekmektedir. Böyle bir okuma teklifinde, asıl sorun ańıtayın kısmındadır, çünkü ańıt- fiili yapısı bakımdan tartışmalıdır. Cümledeki ańıt-'in üzerinde 'volitional' işlevine sahip \{-(A)yIn\} eki bulunmaktadır. Ek, 


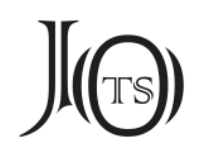

cümlenin bağlamı açısından uygundur. Ekin getirildiği gövde ańıt- < ań-1t- şeklinde tahlil edilebilir. Böyle bir tahlilde bir ań- kökü düşünülmelidir.

Kanaatimizce, ań- ve ańıt- fiillerinin doğru anlamı, bunların ańıg ile ilişkisinin doğru tespit edilmesiyle ortaya çıkarılabilir. Eski Türkçe ańıg'ın ań- ve ańıtile ilgili olduğu daha önce dile getirilmiştir. Bu nedenle, ańıg üzerinde biraz durmak istiyoruz.

CLAUSON, anıg'ın yapısı ve kökeni hakkında bir açıklama yapmamış, sadece kelimenin iki farklı anlamını zikretmiş̧tir: 'çok(ça), epey(ce)' ve 'kötü(ce)'. Ayrıca, alıg 'alık, aptal' kelimesinin aslında ańıg ile eşanlamlı olduğunu ve muhtemelen ańg'ın ikincil şekli olduğunu belirtmiştir (1972: 135b, 182a).

ERDAL, anıı'ın ayın- 'korkmak' ile ilgili olduğunu, *aynıg'ın (< ayın-ıg) daha sonra büzülmeyle anıı hâlini aldığını ve ańg'ın ayın-'in 'indirect object'i olduğunu belirtmiştir. Ona göre, /ń/, ön damak /n/'si değil, genizsil /y/'dir (1991: 181-182).

Şimdiye kadar ańı için genellikle 'kötü, fena' anlamı gösterilmiştir. Bu anlamlandırma şüphesiz doğrudur, ama ań- fiilinin anlamının belirlenmesinde bu anlamlandırma tam olarak faydalı olmamaktadır. Eski Türkçede $\{-(\mathrm{X}) g\}$ eki, bazı örneklerde geçişsiz fiilin fâilini gösteren isimler yapmaktadır (Erdal 1991: 222223). Buna göre, ańıg için 'kötü, fena' anlamı düşünülürse, ań-'in da 'kötü olmak, fena olmak' gibi bir anlamının düşünülmesi gerekecektir. Ancak şimdiye kadar ań- ve ańtt- için önerilen anlamlar arasında böyle bir anlama rastlanmamaktadır. O hâlde, *ań-'in başka bir anlamı olmalıdır.

Kanaatimizce, ań- fiilinin asıl anlamı 'yok olmak, kaybolmak' olarak düşünülebilir. ${ }^{1}$ Bu temel anlamdan gelişen ikinci anlam da 'zarar vermek, yıkmak, yok etmek' olmalıdır. Düşündüğümüz bu temel anlamdan hareketle ańıg için 'zarar, yokluk' anlamı net olarak ortaya çıkmaktadır. Kelimedeki bu anlam gelişiminin

Dîvânü Lugati't-Türk’te Kaşgârî̀nin Oğuzca olarak kaydettiği ạ (= Arapça lā) 'yok' (Ercilasun-Akkoyunlu 2014: 32 [s. 19]) muhtemelen ań- ile ilgilidir. 


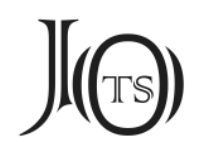

benzerini Arapçada da takip edebiliyoruz: $z \bar{a}$ ' 'kaybolmak, yok olmak; mahvetmek, bozmak, yıkmak, zarar vermek'; $z \bar{a} y \bar{a}$ ' 'kayıp, zarar, yıkım, harap'; $z \bar{a} ' i$ ' 'kayıp, zavallı, sefil' (Wehr 1976: 547b-548a).

Aynı şekilde, Türkçedeki 'yokluk' ve 'kötülük' kavramları arasındaki ilişki için bugün Türkiye Türkçesinde Arapça alıntı olarak kullanılan fenā' kelimesi de iyi bir örnektir. Bu alıntı, Osmanlı Türkçesinde hem 'kötü' hem de 'yokluk' anlamında kullanılmıştır. Aslında dünya dillerinde 'yokluk, kayıp' ile 'zarar' arasındaki ilişkiyi açıkça gösteren pek çok kelimeye daha rastlıyoruz. Mesela, İngilizce loss, perdition, perish, damage; Almanca das Verlust; Fransizca perte, vs.

Dolayısıyla, 'yokluk', 'kayıp' kavramindan 'zarar' ve yine bu kavramdan 'kötü' anlamının ortaya çıkması kolaylıkla anlaşılabilmektedir. Buna göre, Eski Türk yazıtlarında ańıg'ın geçtiği yerlerde kelimenin 'kötü’ anlamı yanında, 'zarar, zararlı' anlamının da düşünülmesi metnin bağlamının daha net anlaşılmasını sağlayacaktır. Krş. KT G5 = BK K4, KT G7 = BK K5, T34. Ayrıca, ulamtı ${ }^{2}$ ańıg yok (KT G3 = BK K2) cümlesinde ańıg'1 'yokluk' temel anlamina dayanarak 'sefalet' şeklinde anlamlandırmak metnin bağlamı açısından daha uygun gözükmektedir.

Eski Türk yazıtlarında ańıg'ın edgü ile karşıt anlamlılık sergilediği görülmektedir. Bu karşıtlık, aslında ańı'ın anlamının daha net görülmesine yardımcı olabilir. Mesela, edgü şu cümlede, 'zararlı' anlamındaki ańg'ın zıttı olarak 'fayda, faydalı' anlamındadır: edgü körteçi sen (BK K14). Eski Türkçede edgü'nün bu anlamı Uygurca metinlerde de görülmektedir. Krş. ulug törlüg asıgka edgüke tegür'zu großartigen Vorteil ${ }_{2}$ gelangen lassen' (Röhrborn 2017: 142); y(a)rlıkamakınıznıy ok edgüsi tétir 'ist der Vorteil davon, dass Ihr geruht habt (...)' (Röhrborn 2017: 142).

Yakutça ayī 'günah' (Sleptsova 1972: 35b) ve Dolganca ań ańi 'günah' (Stachowski 1993: 34) kelimelerinin Eski Türkçe ańıg ile ilişkili olduğu tahmin edilmektedir (Stachowski 1993b: 98-99). Eski Türkçedeki 'zarar, zararlı' anlamında düşündüğümüz ańı'ın bu anlamından hareketle Yakutçada 'günah' anlamının ortaya çıkması açıklanabilir gibi gözükmektedir. Bu anlam gelişimi için

DOERFER, ol amtı yerine ulamtı 'ayrıca, bundan başka' okunuşunu teklif etmiştir (1965: 195). 


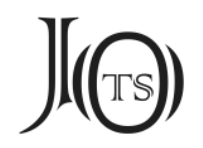

Türkçeye Farsçadan geçen gunāh alıntısı iyi bir örnektir. Krş. Pehlevice wināh'bozmak, y1kmak' wināh 'günah, suç' > Farsça gunāh (Mackenzie 1986: 91).

O hâlde, anıg'ın Eski Türk yazıtlarında '1. zarar, zararlı; 2. kötü; 3. korkunç; 4. pek çok, aşırı’ anlamlarının olduğu söylenebilir.

Runik harfli metinlerde kelimenin 'korkunç' anlamına rastlanmasa da 'pek çok, aşırı' anlamının bu anlam üzerinden ortaya çıtı̆̆ı tahmin edilebilir's ańıg edgü 'olağanüstü iyi', ańıg yablak 'aşırı kötü', vb. Bu mecazlaşmadan dolayı ańıg, Türkiye Türkçesindeki korkunç ve dehşet sözcükleriyle karşılaştırılabilir: korkunç zeki, dehşet güzel, vb. (Şirin 2015: 66). Ayrıca krş. İngilizce awful 'korku' $\rightarrow$ awfully 'aşırı, pek çok'; Arapça dahişa 'korkmak, şaşırmak' $\rightarrow$ mudhiş 'çok, pek fazla', vs.

Begire yazıtının (E 11) 6. satırının sonunda neşirlerde $(a) z d(l) m$ şeklinde okunan bir kelime bulunur. Bu kelimedeki ilk harf, bütün nâşirler tarafından RADLOFF'tan (1895: 316) beri /z/ olarak kabul edilmiştir. SERTKAYA, 1991 y1lında VASILYEV ile beraber yazıtı bizzat yerinde (Güney Sibirya) inceleme imkânı bulmuştur.

SERTKAYA, şunu söylemektedir:

\begin{abstract}
“Orijinal metinde ise Radloff, Orkun, Malov ve Vasilyev'in Z okuduğu ligatür çok açık bir şekilde ń olarak teşhis edilmektedir ve metinde $\$$ şeklinde olmak üzere ayna pozisyonunda yazılmıştır". ${ }^{4}$
\end{abstract}

SERTKAYA, buna dayanarak, Begire (E 11) yazıtında ńdm şeklinde geçen kelimenin (a)ńd(ı)m ‘öldüm' şeklinde okunmasını teklif eder. Ayrıca, Tekin 1968'de ań- ve ańıt- için önerilen 'korkmak' ve 'korkutmak' anlamlarının ‘ölmek' ve 'öldürmek' şeklinde değiştirilebileceğini ve ańıg'ın kökünün ań-’a dayandığını belirtmiştir (1995: 69-71).

HAMILTON'a göre, Uygurcadaki ayıg kelimesinin anlamı 'kötülük' kavramından 'çok' kavramına geçiş şeklinde gerçekleşmiştir. Bunun için Fransızca méchamment 'kötü' $\rightarrow$ vachammet 'çok' örneği gösterilmiştir (1998: 169b).

4 VASIL'YEV'in runa listesinde / $\mathrm{z} /$ karşllı̆̆ında gösterilen \& işareti yedi yazıtta daha tespit edilmiştir: E 11, 26, 27, 59, 100, 108, 109 (1983: 142). Ancak bahsedilen harf, bu yazıtların hepsinde şekil bakımından aynı değildir. Bu nedenle, VASiL'YEV'in tespitine ihtiyatla yaklaşılmalıdır. 


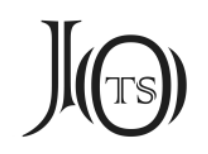

SERTKAYA'nın ań- ve ańıt- fiillerinin anlamını 'ölmek' ve 'öldürmek' şeklinde düşünmesi oldukça isabetlidir. Yukarıda da belirttiğimiz üzere, ań- fiilinin asıl anlamı 'yok olmak' şeklinde düşünüldüğünde 'ölmek' anlamının kelimenin temel anlamından ortaya çıkmış olması oldukça muhtemeldir. Zaten Eski Türk yazıtlarında 'ölmek' kavramı yok bol- ile de ifade edilmiştir (Roux 1984: 139-141).

Kanaatimizce, 'yok etmek' anlamındaki ańıt- fiili Şine Usu yazıtının doğu cephesinin 8. satırında da geçmektedir: tatarıg ayıtdım. Yazıttaki ayıtdım hakkında ŞíRíN tarafından bir makale yazılmıştır. Ona göre, ańt-'ın ikincil biçimi ayıt- 'korkutmak' olmalıdır ve /ń/ genizsilliğini yitirip ön damaksıllaşarak /y/ olmuştur: ańıt- > ayıt-. Buna benzer seslik gelişim Ongin yazıtının 1. satırında da görülür: yań- > yay- 'yaymak, dağıtmak; bozguna uğratmak'. Ayrıca, ańıg 'kötü, fena' ile *ań-, ańt- 'korkutmak, tedhiş etmek' ve Uygurcadaki ayın- 'korkmak' aynı ailenin üyeleridir. (2008: 183-196)

ŞíRiN, bu anlamlandırmasına dayanak olarak oldukça dikkate değer bir tespitte bulunmaktadır:

\begin{abstract}
"Orduyu sefere çıkarmak" çok ciddi hazırlık gerektiren bir eylemdir ve ancak düşman bir bodunu/boyu dize getirmek veya bir bölgeyi fetih/zapt etmek için yapılır. Bir boyu "konuşturmak, soruşturmak” için sülemek/yorılt(t)mak işine girişilmez. Köktürk ve Ötüken Uygur kağanlığı yazıtlarında süle- ve yort- fiillerinden oluşan cümlelerden sonra gelen diğer cümlelerin yüklemi, her zaman b(a)s- "baskın yapmak"; süy(ü)ş- "savaşmak"; (a)l- "ele geçirmek, fethetmek, zapt etmek"; $b(a) z$ kll- "itaat altına almak, bağıml kılmak, kendi siyasal oluşumuna dâhil etmek, ilhak etmek"; boz- "tahrip etmek, yıkmak, dağıtmak"; tir- "başka bodun ve boyları kendi müttefiki kılmak"; kubr(a)t- "başka bodun ve boyları kendi müttefiki kılmak", tokı- "kılıç veya mızrakla vurmak; savaş yapmak" gibi savaşla doğrudan ilgili eylemler olmuştur. (Şirin 2008: 190-191)
\end{abstract}

Eski Türk yazıtlarında askerî sefer düzenlemenin belirli şartlara bağlı olduğu görülmektedir. Şíín’in de belirttiği üzere ‘soruşturma' amaciyla askerî sefer düzenlemek pek mantıklı değildir. Bu tespite katılmakla beraber, askerî sefer düzenleme nedeni olarak 'korkutma' gayesinin güdülmesi de kanaatimizce çok mantıklı değildir. Askerî sefer düzenlemenin yegâne gayesi 'fethetmek' ve 'boyunduruk altına almak' amacıyladır. Şine Usu yazıtındaki bağlamdan anlaşılacağı

Aynı görüş ve kelimenin okunuşu üzerine daha önce ileri sürülen öneriler için ayrıca bk. Şirin 2016: 128-129. 


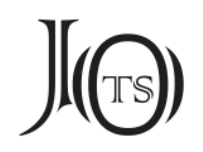

üzere Moyun Çor, Tatarlarla çok ciddi bir mücadelenin içinde gözükmektedir. 0 hâlde, yazıtın doğu cephesinin 8. satırındaki ayıt-'in 'yok etmek, harap etmek, ortadan kaldırmak' anlamında düşünülmesi daha doğru olacaktır.

Muhtemelen *ań- ve ańt-'taki /ń/ fonemi, Uygurcada genizsilliğini yitirip ön damağa geçerek /y/ olmuştur. ${ }^{6}$ Tarihi belli olmayan Mani harfli bir fragmandaki (MIK III 34b [T II T20]) Runik harflerin Mani harfleriyle karşılıklarının gösterildiği bir listede 3 işaretinin Mani harfli karşıllı̆̆ 'YY ıy iy olarak gösterilmiştir (Le Coq 1909: 1050). Bu listeye göre, /ń/ foneminin /y/ olması erken bir dönemde gerçekleşmiş olmalıdır.

Ancak burada başka bir sorun ile karşılaş1lyyor. Uygurcada ayıt- (< ańıt-) 'korkutmak' anlaminda bir fiile rastlanmaz. Bunun sebebi muhtemelen kelimenin eşsesli/eşyazımlı ayıt- 'söylemek' ile birbirine karıştırılmasını önleme düşüncesidir. Bunun yerine ay- 'yok olmak' (< ań-) fiili kaynaklı bazı gövdelere rastlanmaktadır:

\begin{abstract}
ayın- (< *ay-ın-) '1. korkmak, korkmuş olmak, hayretten şaşırmış olmak; 2. utanmak, alçak gönüllü olmak' (Röhrborn 2010: 116-117); ayınç (< *ay-1nç) 'korku, endişe, kaygı, dehşet' (Röhrborn 2017: 94); ayınçlıg (<*ay-1nç+lıg) 'korkudan oluşan, korkuya dayanan' (Röhrborn 2017: 95); ayınçsız (<*ay-1nç+sız) 'korkusu olmayan, korkusuz' (Röhrborn 2017: 95); ayıgla(< *ay-1g+la-) 'aşağılamak, (bir kişiyi) kötülemek, hakaret etmek, iftira etmek' (Röhrborn 2010: 115-116); ayıglaş- (<*ay-1g+la-ş-) ‘birbirini aşağılamak, birbirine hakaret etmek, küfretmek' (Röhrborn 2010: 116).
\end{abstract}

Eski Türk yazıtlarında ańıg, Uygurcada ayıg ( * *ay-ıg < *ań-1g) olmuştur. Krş. ayıg '1. talihsizlik, sıkıntı, fenalık, zarar; talihsiz, sıkıntılı, fena, zor, hoş olmayan; 2. günah, kötülük, günahkârlık, (Budizmde ruhsal anlamda) kirlilik, günahkâr, kötü, kirli; 3. dedikodu, söylenti, iftira' (Röhrborn 2017: 82-87).

ÖLMEZ, Moğolların Gizli Tarihi'ndeki Eski Türkçe alıntılar arasında ayaḥu 'fürchten, erchrecken' kelimesini de zikretmiştir. Ona göre, ańıg'ın kökünün ettirgen gövdesi Eski Türkçede ańı- 'korkutmak, tehdit etmek' şeklindedir. Eski Türkçe kelimeler Moğolcada bir ünlü ilavesiyle görüldüğü için Eski Türkçe ań- Moğolcada ayu- şeklini almıştır. Buna göre, Ana Türkçede kelime *ań- şeklinde tasarlanmalıdır (2013: 379). CLAUSON, Eski Türkçe ayın- ile Moğolcadaki (XIII. yüzyıl) ayu-benzerliğini 'tesadüfi' olarak düşünmüştür (1972: 274b). 


\section{J(৫)}

RADLOFF'un Türk Lehçeleri Sözlüğü'nde Şorca olarak kaydettiği ay- 'solmak, (rengi) kaybolmak' (1893: 9) veya Hakasça ay- 'kaybolmak' (Arıkoğlu 2005: 56b; Subrakova 2006: 39b7) kelimeleri belki de Eski Türkçe *ay- (< ań-) ile ilgilidir.

SEVORTYAN'a göre, eymen- ile ayın- aynı köke dayanmaktadır (1974: 249251). Tekin 1996: 267'de de aynı görüş kabul edilmiştir, ancak iki kelime arasında anlamsal bir bağ yoktur. Ayrıca iki kelime arasında korkmak ile beraber ikilemelerde kullanılması dışında herhangi morfolojik bir bağ görülmez. Dolayısıyla iki kelime arasında etimolojik bir ilişkinin düşünülmesi için herhangi bir sebep yoktur (Erdal 1991: 599).

Aynı şekilde Altay Dillerinin Etimolojik Sözlüğü'nde de Eski Türkçe eymenmek ile Moğolca ayu- denkliği düşünülmüştür (Starostin 2003: 496-497), ama bu denklikte anlamsal ortaklık dışında başka bir benzerlik bulunmaz. Bu nedenle eymenmek ile Moğolca ayu-arasındaki yapısal ortaklık izaha muhtaçtır. Ancak POPPE'ye göre Orta Moğolca ayu- < ay-u- 'korkmak' ile Eski Türkçe ayın- 'korkmak, endişelenmek' denkliği mevcuttur (1960: 66).

Eski Türkçede *ań- fiilinin temel anlamını (denotation) 'yok olmak, kaybolmak' ve 'zarar vermek' olarak düşündüğümüzde kelimenin çağrışımsal (connotative) anlamının Uygurcada 'korkmak' şeklinde ortaya çıkması açıklanabiliyor, zira 'zarar vermek' kavramı insanda 'ürperti, korku' duyularını tetiklemektedir. Bunun için krş. İngilizce fear 'korku' < far 'zarar' (Skeat 1888: 205a).

Aslında POPPE ve TEKIN'in İlk Türkçe farazî *ay- köküyle ilişkilendirdiği Moğolca ayu- fiilinin farklı şekilleri de Eski Türkçedeki kelimenin anlam gelişimleriyle benzerlik göstermektedir. Krş. ayu- 'korkmak' (Lessing 1960: 20a), ayumura '1. korkunç, dehşetli; 2. son derece, pek çok, aşırı' (Lessing 1960: 25b); aymur'kötüleşmek, bozulmak' (Lessing 1960: 21b); aydarla- 'bozulmak, ahlak ve davranış bakımından kötüleşmek’ (Lessing 1960: 20a), vs.

Buna göre, illk Türkçe *ań- ‘yok olmak, kaybolmak' kökünden türeyen gövdeler liste hâlinde şöyle gösterilebilir:

Fiil, sözlükte ayarga maddesinde verilmiş ve kelimenin kökü yanlış olarak aya- şeklinde gösterilmiştir. 


\begin{tabular}{|c|}
\hline \\
\hline ca ay- ‘solmak, (rengi) kaybolmak'. \\
\hline 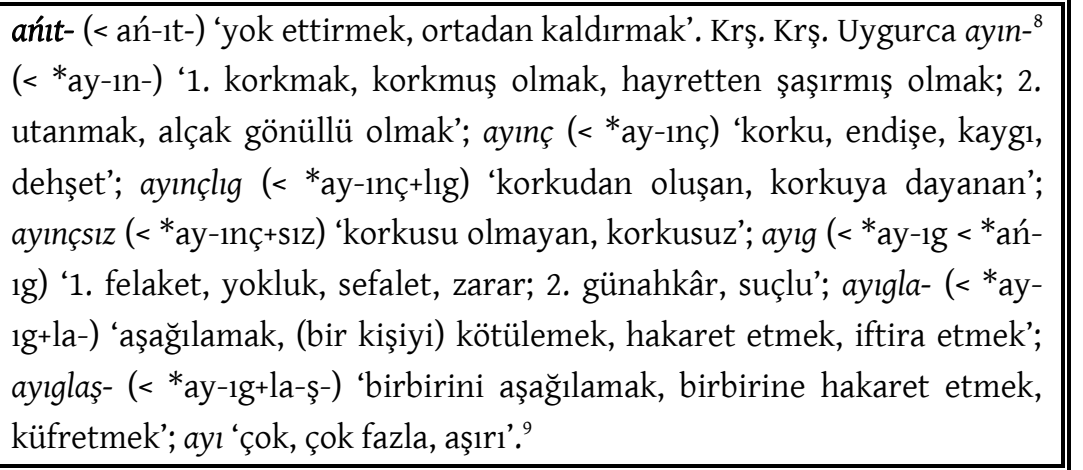 \\
\hline $\begin{array}{l}\text { ańıg (< ań-1g) ‘1. talihsizlik, sıkıntı, fenalık, zarar; talihsiz, sıkıntılı, fena, } \\
\text { zor, hoş olmayan; 2. günah, kötülük, günahkârlık, (Budizmde ruhsal an- } \\
\text { lamda) kirlilik, günahkâr, kötü, kirli; 3. dedikodu, söylenti, iftira'. Krş. Tu- } \\
\text { vaca ançıg 'sıkıcı, bezdirici, can sıkıcı, kötü’ <*anyıg (?) < ańıg (?); Yakutça } \\
\text { ayì 'günah'; Dolganca ańı ańi ' 'günah'. }\end{array}$ \\
\hline
\end{tabular}

Eski Türkçe ańı acaba Yakutça ve Dolganca dışındaki Türk dillerinde de yaşıyor mu? Tuvacada bir kelime vardır: ançıg ‘sıkıcı, bezdirici, can sıkıcı, kötü’ (Ölmez 2007: 75a-b). Kelimenin anlam bakımından ańı ile ilişkisinin olduğu kesindir. Tuvacanin Etimolojik Sözlüğ̈̈'ne göre, kelimenin kökü *ay- *ań- 'korkmak, ürkmek' ya da 'korkutmak' olabilir. Aynı şekilde bk. ayın- 'korkmak, endişelenmek', fakat bu kelimenin temeli fiil değil, isim olabilir. Anlam ve yapı bakımından ançıg kelimesine en yakını biçim Yakutçadaki ançıy-fiilidir. (Sondaki \{-y\} kuvvetlendirme eki), PEKARSKI, bu kelimeyi munna munçuybata, anna ançıybata şeklindeki cümlenin içerisinde kullanmıştır. Cümlenin anlamı "O hiç bir şeye önem vermedi, hiç pişman olmadı” (nedamet etmek) (Tatarintsyev 2000: 117).

TATARINTTSYEV'in Tuvacadaki ançıg'in kökü olarak düşündüğü Yakutça ançıy-'in yapısı ve anlamı ançıg ile ilgili gözükmemektedir. Tuvaca ançıg Eski Türkçe ańı ile ilişkili olabilir. Tuvaca ve Ortak Türkçe arasında kelime başında bir /y-/

\footnotetext{
8 Ayrıca krş. Anadolu Ağızları aymaz ( < *ay-maz ?) ‘edepsiz, utanmaz’ (DS: 426a).

9 Uygurcada ańıg ile ilişkili bir de ayı ‘çok, büyük ölçüde, çok iyi’ (Röhrborn 2017: 80-82) vardır. Kelimenin yapısı hakkında kesin bir şey söylenemiyor, ama RÖHRBORN'a göre ayıg ve ayı Uygurcada klasik öncesi dönemde birbirinden ayrılmış, bu ayrılık klasik dönemde imlâya yansımış olmalıdır (2017: 80-81). Belki de Uygurcada ayı o dönemde henüz tanıklanmamış olan *ay-kökünden $\{-\mathrm{I}\}$ zarffiil eki ile türetilmiştir.
} 


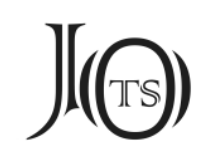

> /ç-/ farklılı̆̆ı bilinmektedir. Belki de Eski Türkçedeki /ń/ ünsüzü genizsilliğini yitirip önce ön damağa geçip /y/ olmuş ve sedalı yarı ünlü hâlindeki /y/ sedasız diş damak ünsüzü /ç/'ye dönüşmüş olmalıdır: ańıg > *anyıg < ançıg (?).

Sonuç olarak, Bilge Bilge Kagan yazıtının doğu cephesinin 41. satırındaki arkışı kelimedi anı ańtayın tép süledim şeklindeki cümlede geçen ibarenin (a)nı (a)ń(i)t(a)y(i)n 'onu yok ettireyim, ortadan kaldırayım' olarak anlamlandırılmasının doğru olabileceğini düşünüyoruz.

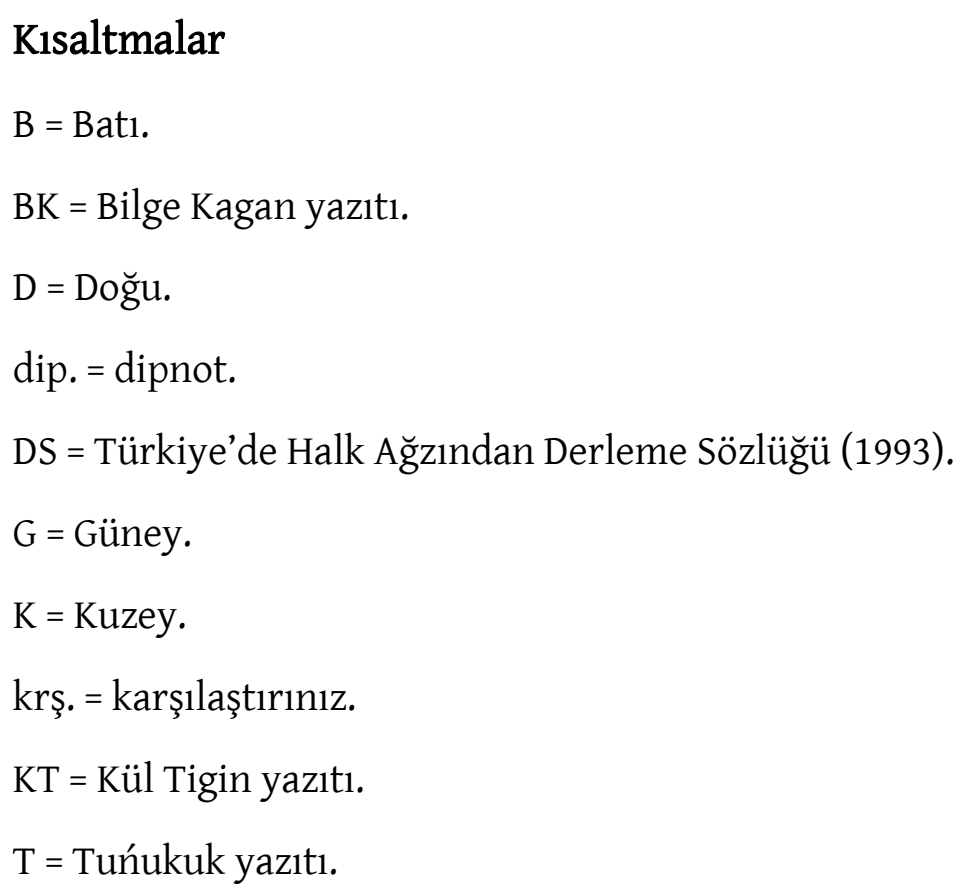

\section{Kaynakça}

ABDURAHMONOV, G.; A. RUSTAMOV (1982). Kadimgi Turkiy Til, Toşkent: Ukituvçi Naşriyeti.

ALYILMAZ, C. (2005). Orhun Yazıtlarının Bugünkü Durumu, Ankara: Kurmay Yayınlar1.

ARIKOĞLU, E. (2005). Örnekli Hakasça-Türkçe Sözlük, Ankara: Akçağ Yayınları.

AYDAROV, G. (1971). Yazkk Orhonskih Pamyatnikov Drevnetyurkskoy Pis'mennosti VIII Veka, Alma-Ata: Nauka. 


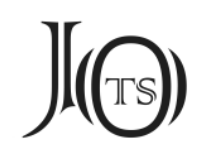

AYDIN, E. (2017). Orhon Yazıtları (Köl Tegin, Bilge Kağan, Tonyukuk, Ongi, Küli Çor), İstanbul: Bilge Kültür Sanat.

BAZILHAN, N. (2005). Kazakstan Tarihi Turalı Türki Derektemeleri, Tom II: Köne Türik Bitiktastarı Men Eskertkişteri (Orhon, Yenisey, Talas), Almatı: "Dayk-Press".

BERTA, Á. (2010). Sözlerimi İyi Dinleyin: Türk ve Uygur Runik Yazıtlarının Karşılaştırmalı Yayını, Çev. E. YILMAZ, Ankara: Türk Dil Kurumu Yayınları.

CHAVANNES, E. (1903). Documents sur les Tou-Kiue (Turcs) Occidentaux, S. Pétersbourg: Tipografiya İmperatorskoy Akademii Nauk'.

CLAUSON, Sir G. (1972). An Etymological Dictionary of Pre-Thirteenth Century Turkish, Oxford: Oxford University Press.

DOERFER, G. (1965). Türkische und Mongolische Elemente im Neupersischen, unter besonderer Berücksichtigung älterer Neupersischer Geschichtsquellen, vor allem der Mongolen- und Timuridenszeit, Band II, Wiesbaden: Franz Steiner Verlag.

DOERFER, G. (1992). “Bemerkungen zu Talât Tekins Orhon Yazıtları”, Türk Dilleri Araştırmaları, 2: 5-17.

ERCİLASUN, A. B. (2016). Türk Kağanlığı ve Türk Bengü Taşları, İstanbul: Dergâh Yayınları.

ERCILASUN, A. B.; Z. AKKOYUNLU (2014), Kâşgarlı Mahmud: Dîvânu Lugâti't-Türk, Giriş-Metin-Çeviri-Notlar-Dizin, Ankara: Türk Dil Kurumu Yayınları.

ERDAL, M. (1991). Old Turkic Word Formation, a functional approach to the lexicon, Vol. I-II, Wiesbaden: Harrassowitz Verlag.

ERGIN, M. (1970). Orhun Abideleri, Ankara: Milli Eğitim Kitapları.

ERKOÇ, H. İ. (2008). Eski Türklerde Devlet Teşkilâtı (Gök Türk Dönemi), Hacettepe Üniversitesi, Sosyal Bilimler Enstitüsü, Tarih Anabilim Dalı, Ankara. (Yayımlanmamış Yüksek Lisans Tezi)

HAMILTON, J. R. (1998). Budacı İyi ve Kötü Kalpli Prens Masalının Uygurcası, Kalyāṇaṃkara ve Pāpaṃkara, Çev. E. KORKUT; İ. BİRKAN, Ankara: Simurg Yayınları.

HUDIYYEV, N. (2015). Qedim Türk Yazılı Abidelerinin Dili, Bakı: Élim ve Tehsil.

Inscriptions de l'Orkhon (1892). Recueillies par l'expédition Finnoise 1890, Société Finno-Ougrienne, Helsingfors: Imprimerie de la Société de Littérature Finnoise. 


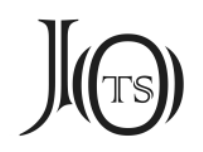

KARCAUBAY, S. (2003). Orhon Muraları: Tarihnamalık-Derektanulık Taldau, 1 Kitap, Astana: Kultegin.

LE COQ, A. von (1909). "Köktürkisches aus Turfan (Manuskriptfragmente in köktürkischen 'Runen' aus Toyoq und Idiqut-Schähri [Oase von Turfan]”, Sitzungsberichte der Königlich Preußischen Akademie der Wissenschaften, 1909: 41: 1047-1061.

LESSING, F. D. (1960). Mongolian-English Dictionary, Bloomington-Indiana: The Mongolia Society.

MACKENZIE, D. N. (1986). A Concise Pahlavi Dictionary, London: Oxford University Press.

MALOV, S. E. (1959). Pamyatniki Drevnetyurkskoy Pis'mennosti Mongolii i Kirgizii, Moskva-Leningrad: İzdatel'stvo Akademii Nauk SSSR.

NADELYAYEV, V. M. et al (1969). Drevnetyurkskiy Slovar', Leningrad: İzdatel'stvo "Nauka" Leningradskoye Otdeleniye Leningrad.

ORKUN, H. N. (1936). Eski Türk Yazıtları I, İstanbul: Devlet Basımevi.

ÖLMEZ, M. (2007). Tuvacanın Sözvarlığı (Eski Türkçe ve Moğolca Denkleriyle), Wiesbaden: Harrassowitz Verlag.

ÖLMEZ, M. (2012). Moğolistan'daki Eski Türk Yazıtları, Orhon-Uygur Hanlığı Dönemi: Metin-Çeviri-Sözlük, Ankara: Bilge-Su Yayıncılık.

ÖLMEZ, M. (2013). “Moğolların Gizli Tarihi ve Sözvarlığı Üzerine”, Bengü Beläk: Ahmet Bican ERCILASUN Armağanı, Ed. B. GÜL, Türk Kültürünü Araştırma Enstitüsü Yayınları, Ankara: 377-384.

POPPE, N. (1960). Vergleichende Grammatik der altaischen Sprachen, Teil I: Vergleichende Lautlehre, Wiesbaden, Otto Harrassowitz.

RADLOFF, W. (1893). Versuch eines Wörterbuches der Türk-Dialecte, Erster Band: die Vocale, St. Pétersbourg: Imperatorskaya Akademiya Nauk.

RADLOFF, W. (1895). Die alttürkischen Inschriften der Mongolei, St. Petersburg: Buchdruckerei der kaiserlichen Akademie der Wissenschaften.

RADLOFF, W. (1896). Atlas der Alterthümer der Mongolei, Dritte Lieferung, St. Petersburg: Buchdruckerei der Akademie der Wissenschaften.

RECEBLİ, E. (2009). Qedim Türk Yazısı Abideleri, 4 Cildde, 1 Cild: Göytürk Yazısı Abideleri, I Hisse, Bakı: Nurlan. 


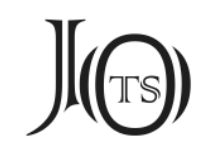

ROUX, J. P. (1984). “Le vocabulaire de la mort chez les anciens Turcs”, Ural-altaische Jahrbücher Neue Folge, 4: 134-149.

RÖHRBORN, K. (2010). Uigurisches Wörterbuch, Sprachmaterial der vorislamischen türkischen Texte aus Zentralasien, Neubearbeitung, I: Verben, Band 1: ab- - äzüglä, Stuttgart: Franz Steiner Verlag.

RÖHRBORN, K. (2017). Uigurisches Wörterbuch, Sprachmaterial der vorislamischen türkischen Texte aus Zentralasien, Neubearbeitung, II. Nomina, Pronomina, Partikeln, Band 2: aš - äžük, Stuttgart: Franz Steiner Verlag.

SERTKAYA, O. F. (1995). “Göktürk Tarihinin Meseleleri: Yenisey Yazıtlarının Yayınlarındaki Bazı Okuma ve Anlamlandırmaların Düzeltilmesi, Yeni Okuma ve Anlamlandırma Teklifleri”, Türk Dili Araştırmaları Yıllığı Belleten 1993: 67-75.

SEVORTYAN, E. V. (1974). Etimologiçeskiy Slovar Tyurkskih Yazıkov (Obşçetyukskiye i Mectyurkskiye Osnovı na Glasnıye), Moskva: İzdatel'stvo “Nauka”.

SKEAT, W. W. (1888). An Etymological Dictionary of the English Language, Oxford: Clarendon Press.

SLEPTSOVA, P. A. (1972). Yakutsko-Russkiy Slovar', Moskva: İzdatel'stvo “Sovyetskaya Entsiklopediya".

STACHOWSKI, M. (1993a). Dolganischer Wortschatz, Kraków: Uniwersytet Jagielloński.

STACHOWSKI, M. (1993b). Geschichte des jakutischen Vokalismus, Kraków: Uniwersytet Jagielloński.

STAROSTIN, S. et al (2003). Etymological Dictionary of the Altaic Languages, Vol. I-III, E. J. Brill: Leiden-Boston.

SUBRAKOVA, O. V. (2006). Hakassko-Russkiy Slovar' (Okolo 22 tis. Slov). Novosibirsk: "Nauka".

SULTANZADE, V. (2017). “Türk Runik Alfabesindeki 'Çift Ünsüz’ İşaretleri Üzerine", Bilig, 82: 201-216.

ŞAYMERDINOVA, N. G. (2014). Drevnetyurkskaya Kartina Mira v Tekstah Pis'mennıh Pamyatnikov, Uçebneye Posobiye, Astana: S Izdatel'stvo ENU im. L. Gumilyeva.

ŞİRIN, H. (2008) “Şine Usu Yazıtı'nda Kayıtlı 't(a)t(a)r(1)g:(a)y(1)td(1)m' Cümlesi Üzerine”, International Journal of Central Asian Studies, 12: 183-196. 


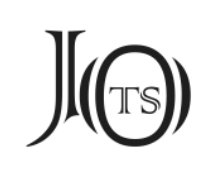

ŞiRìN, H. (2016). Eski Türk Yazıtları Söz Varlığı İncelemesi, Ankara: Türk Dil Kurumu Yayınları.

ŞÜKÜRLÜ, E. (1993). Qedim Türk Yazılı Abidelerinin Dili, Bakı: Maarif Neşriyyatı.

TATARINTSYEV, B. İ. (2000). Etimologiçeskiy Slovar' Tuvinskogo Yazıka, Tom I: AБ, Novosibirsk: "Nauka".

TEKIN, T. (1968). A Grammar of Orkhon Turkic, Bloomington: Indiana University.

TEKIN, T. (1988). Orhon Yazıtları, Ankara: Türk Dil Kurumu Yayınları.

TEKIN, T. (1996). "Altaic Etymologies I", International Journal of Central Asian Studies, 1: 245-268.

THOMSEN, V. (2002). Orhon Yazıtları Araştırmaları: [1.] Orhon ve Yenisey Yazıtlarının Çözümü İlk Bildiri; [2.] V. Thomsen Tarafından Çözülmüş Orhon Yazıtları; [3.] Yenisey Yazıtlarındaki İyi Değerlendirilmemiş Bir Harf; [4.] Turcica, Çeviren ve Yayıma Haz. V. KÖKEN, Ankara: Türk Dil Kurumu Yayınları. [ $\rightarrow$ Inscriptions de l'Orkhon déchiffrées, Imprimerie de la Société de Littérature Finnoise, Helsingfors 1896]

TUGUŞEVA, L. Yu. (2008). Tyurkskiye Runiçeskiye Pis'mennıye Pamyatniki iz Mongolii, Moskva: İnsan.

Türkiye'de Halk Ağzından Derleme Sözlüğü (1993). 12 Cilt, 2. Baskı, Ankara: Türk Dil Kurumu Yayınları.

VASIL'YEV, D. D. (1983). Grafiçeskiy Fond Pamyatnikov Pis'mennosti Aziatskogo Ariala (Opıt Sistematizatsii), Moskva: İzdatel'stvo "Nauka" Glavnaya Vostoçnoy Literaturı.

WEHR, H. (1976). Dictionary of Modern Written Arabic, Ed. J. M. COWAN, 3. Edition, New York: Spoken Language Services. 